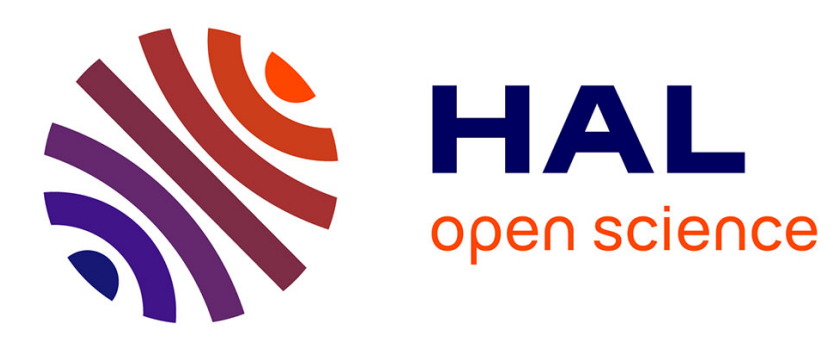

\title{
Cameron Browne: Evolutionary game design, Springer briefs in computer science series
}

\author{
Amine Boumaza
}

\section{To cite this version:}

Amine Boumaza. Cameron Browne: Evolutionary game design, Springer briefs in computer science series. Genetic Programming and Evolvable Machines, 2012, 13 (3), 10.1007/s10710-012-9165-6 . hal-01204965

\section{HAL Id: hal-01204965 \\ https://hal.inria.fr/hal-01204965}

Submitted on 4 Dec 2015

HAL is a multi-disciplinary open access archive for the deposit and dissemination of scientific research documents, whether they are published or not. The documents may come from teaching and research institutions in France or abroad, or from public or private research centers.
L'archive ouverte pluridisciplinaire HAL, est destinée au dépôt et à la diffusion de documents scientifiques de niveau recherche, publiés ou non, émanant des établissements d'enseignement et de recherche français ou étrangers, des laboratoires publics ou privés.

\section{다)(1) $(5$}

Distributed under a Creative Commons Attribution - NonCommerciall 4.0 International 
Boumaza, Cameron Browne: Evolutionary game design, Springer briefs in computer science series. In Genetic Programming and Evolvable Machines, 13 (3): 407-409, 2012.

\title{
Cameron Browne: Evolutionary game design, Springer briefs in computer science series
}

\author{
Amine Boumaza \\ Univ. Lille Nord de France, F-59000 Lille, France, \\ ULCO, LISIC, F-62100 Calais, France \\ boumaza@lisic.univ-littoral.fr
}

How can computers create interesting games? What makes a game interesting and how can a machine decide if a game is of interest to humans? These are among the questions I asked myself when I was asked to review Cameron Brown's book Evolutionary game design. Fortunately, after reading it I had some answers.

It begins by the introduction of "Yavalath", the first commercially released board game that was entirely designed by a machine. After reading this short introduction, I was glued to the book by the desire to understand the central thesis: how can humans design machines that design games for humans? It lead me through the different design steps, as if I was reading a story; the story of the genesis of Yavalath.

Following this introduction, chapter 2 describes the class of combinatorial games and their elements. Combinatorial games include those that are discrete and deterministic with no hidden information, such as chess. Chapter 2 focuses on the elements of such games that can be modified to create new games variants. In chapter 3, Cameron Brown describes the "Ludi" system, the software architecture that designs games. In a nutshell, this architecture invents new games from a set source games using genetic programming. The components of this architecture are discussed individually in later chapters. Chapter 3 introduces the Game Description Language a high level lisp style language that fully describes the game rules, the board and the winning conditions. It goes on to describe the General Game Player, the second component of the Ludi system, which plays games by simulating two players using a set of predefined strategies and using alpha-beta adversarial search. At this stage the reader has a general idea on how the machine creates games. The other question, "how does it decide if a game is interesting?" is answered in chapter 4.

The fourth chapter is the most important as it describes the criteria used to measure the quality of a game. It starts by introducing the attributes that measure, as Cameron Browne elegantly puts it, the "intellectual appeal; the elegance of the rules ... and the quality of the competition they produce". These quality measures are described in detail in an appendix, chapter 4 only gives a few details on some of them. Enough that the reader has the general idea. For exam- 
ple "drama" measures the chance a player has to recover from bad positions. Or "uncertainty" which measures the uncertainty in the game outcome. The most interesting part in chapter 4 is the way these subjective measures are quantified.

At this stage, we have all the ingredients: a mean of representing games and a mean of evaluating their quality, all that is left is a way to evolve them and produce new games. This is the theme of chapter 5 which describes the elements of the genetic programming engine used to evolve the game description language. It describes how games are combined to produce new candidates; how they are modified and how their viability is verified. Chapter 5 ends with an interesting experiment that compares the quality of the evolved games as given by the quality measures with measures given by human test subjects.

Chapters 6 and 7 describe different games produced using Ludi. These games are presented in order of human preference along with their rules as produced by the evolutionary process. In chapter 7 , the focus is on Yavalath. This game was ranked second by the human subjects and fourth by the machine. Incidentally Pentalath, the game that was ranked first by the machine was also ranked first by the human subjects. It however is more complex and deeper than Yavalath, which is simpler and more engaging. Yavalath is described and the interesting game situations are detailed. Chapter 7 also discusses the features of the game that lead to its commercialization.

Cameron Browne finishes with a discussion of the Ludi system, evolutionary game design and computational creativity. He leaves the reader with an interesting fact that raises further questions, he explains that there is nothing in the rules of the games designed by Ludi, that was not introduced in the initial rules given to the system. He also argues that the next step should be one where the "creative process should be attributed more to the machine than to the programmer". This part is rather short and I was left hanging expecting a more in-depth discussion.

Finally, the interested reader can find in the appendices many details about the game description language and the quality measures that evaluates games. The references section is also a good source of information, it includes references from many fields ranging from psychology to evolutionary computation passing by game theory and artificial intelligence.

The electronic version of the book is available on the "springerlink" web site as PDF where the chapters are packaged individually along with the appendices, the references and the index. One advantage over the printed version is that the figures are in color which makes them more legible than on the printed version where they are in black and white. Furthermore, all the citations to the figures, tables and the references are in the form of hyperlinks, which is useful.

Evolutionary Game Design is a valuable contribution to evolutionary computation and more generally to artificial intelligence. It is engaging to read, easy to follow and lives up to its promises. Furthermore, it delivers insights that should be helpful to anyone interested in AI and games. In the beginning, Cameron Browne cites Leibniz who once said "Human being are never more ingenious than in the invention of games". In my opinion, Evolutionary Game Design says how to transfer parts of this ingenuity to the machine. 